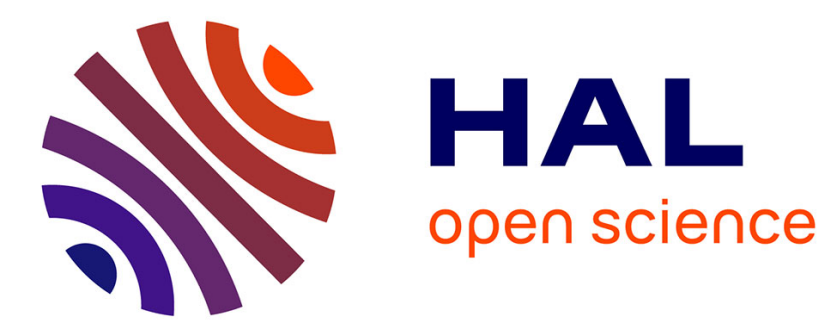

\title{
Root functional architecture: A framework for modeling the interplay between roots and soil
}

\author{
Alain Pierret, C. Doussan, Yvan Capowiez, F. Bastardie, L. Pagès
}

\section{To cite this version:}

Alain Pierret, C. Doussan, Yvan Capowiez, F. Bastardie, L. Pagès. Root functional architecture: A framework for modeling the interplay between roots and soil. Vadose Zone Journal, 2007, 6 (2), pp.269-281. 10.2136/vzj2006.0067 . ird-00190010

\section{HAL Id: ird-00190010 https://hal.ird.fr/ird-00190010}

Submitted on 23 Nov 2007

HAL is a multi-disciplinary open access archive for the deposit and dissemination of scientific research documents, whether they are published or not. The documents may come from teaching and research institutions in France or abroad, or from public or private research centers.
L'archive ouverte pluridisciplinaire $\mathbf{H A L}$, est destinée au dépôt et à la diffusion de documents scientifiques de niveau recherche, publiés ou non, émanant des établissements d'enseignement et de recherche français ou étrangers, des laboratoires publics ou privés. 

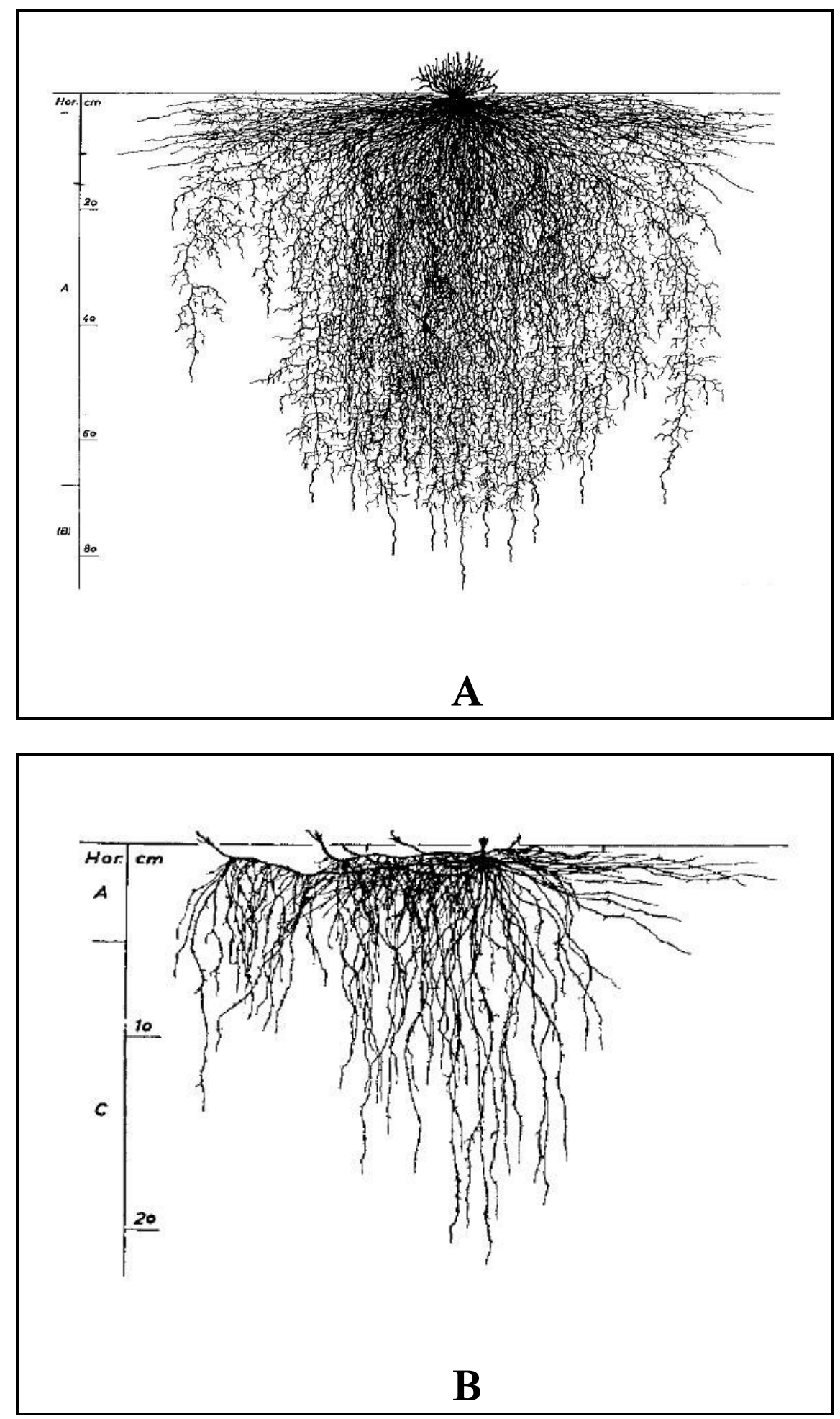

Figure 1 


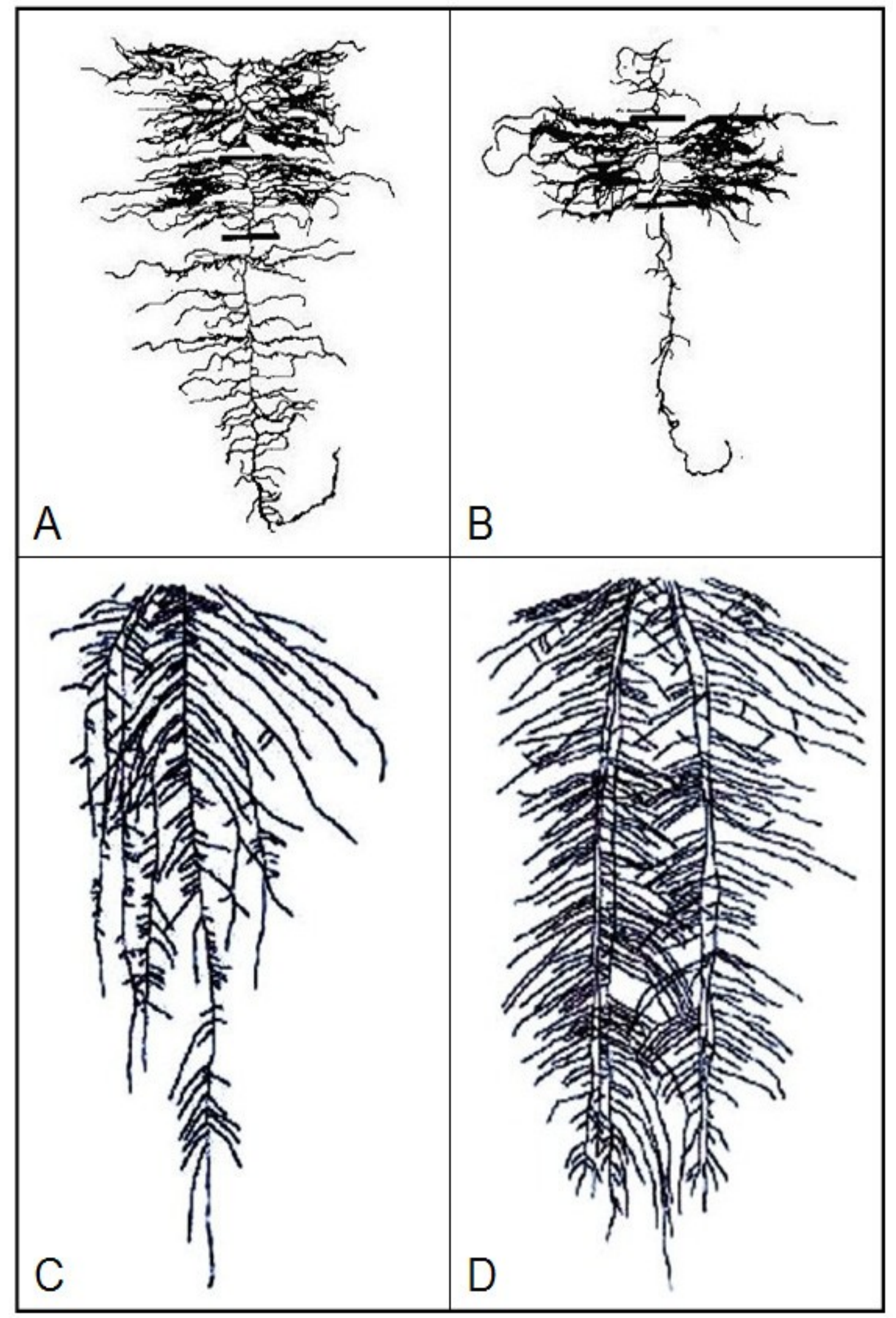

Figure 2 


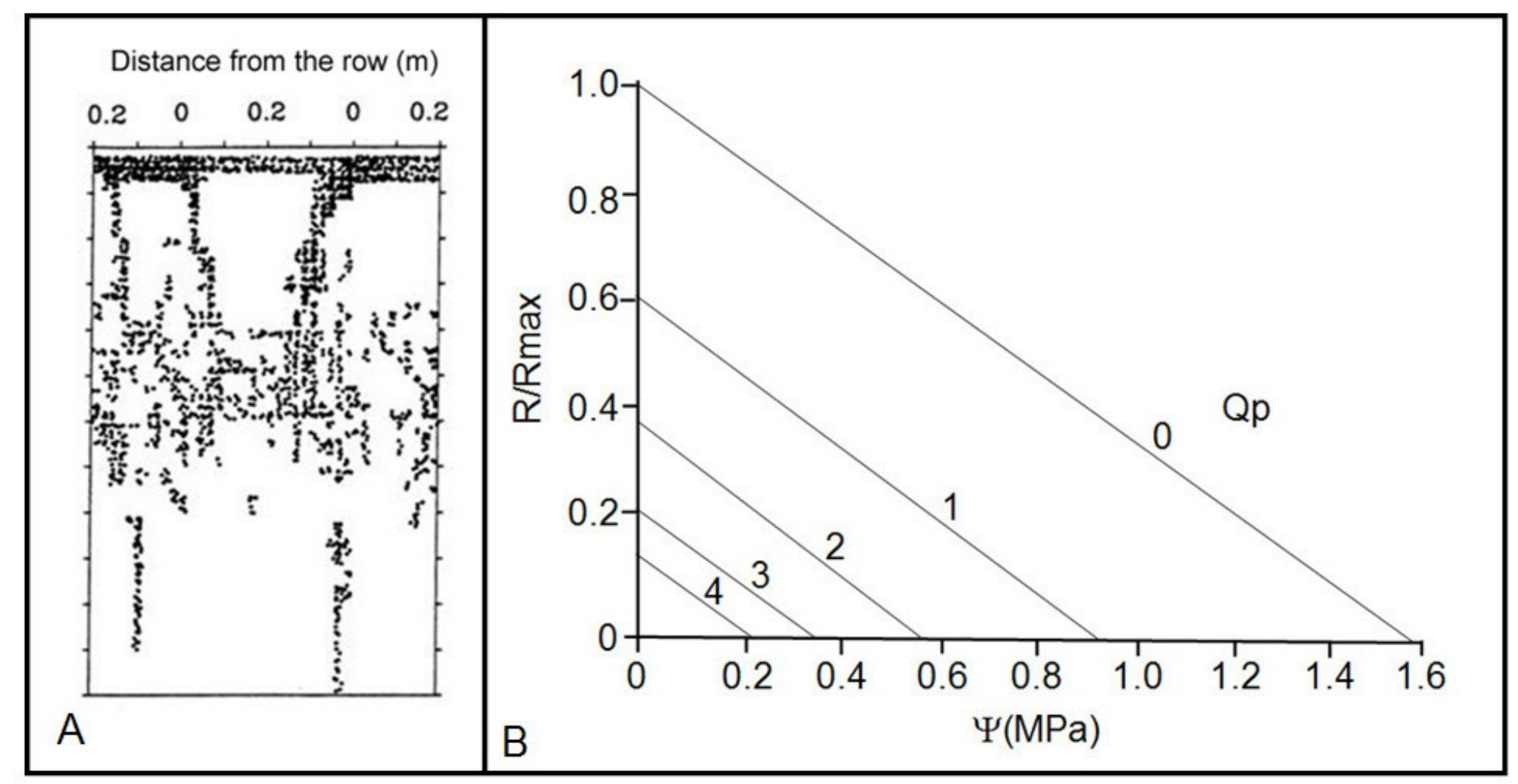

Figure 3 


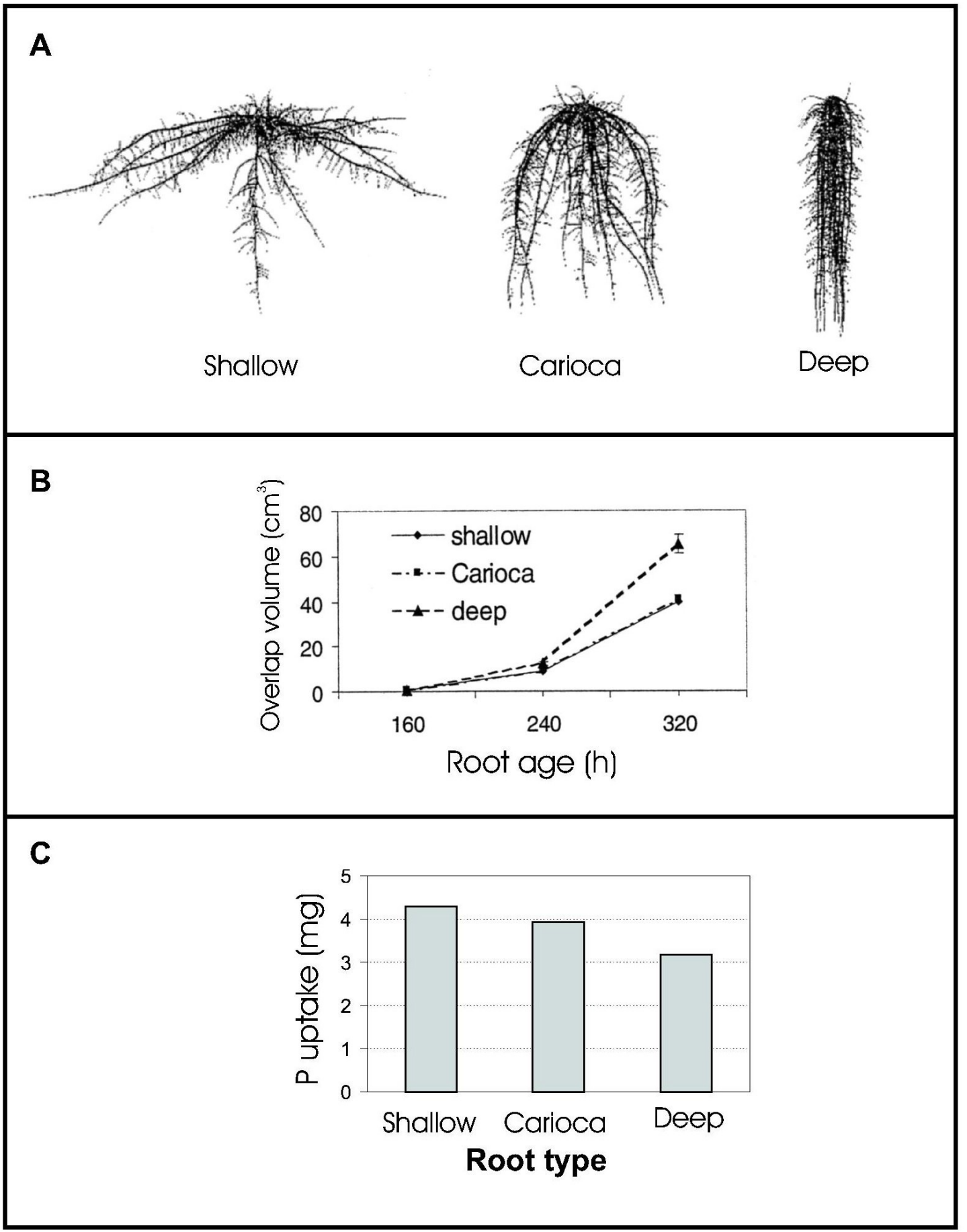

Figure 4 
Root density $\left(\mathrm{cm}^{\left.-\mathrm{cm}^{3}\right)} \quad \mathrm{NO}_{3}\right.$ concentration $\left(\mu \mathrm{M} \mathrm{cm}^{-3}\right)$

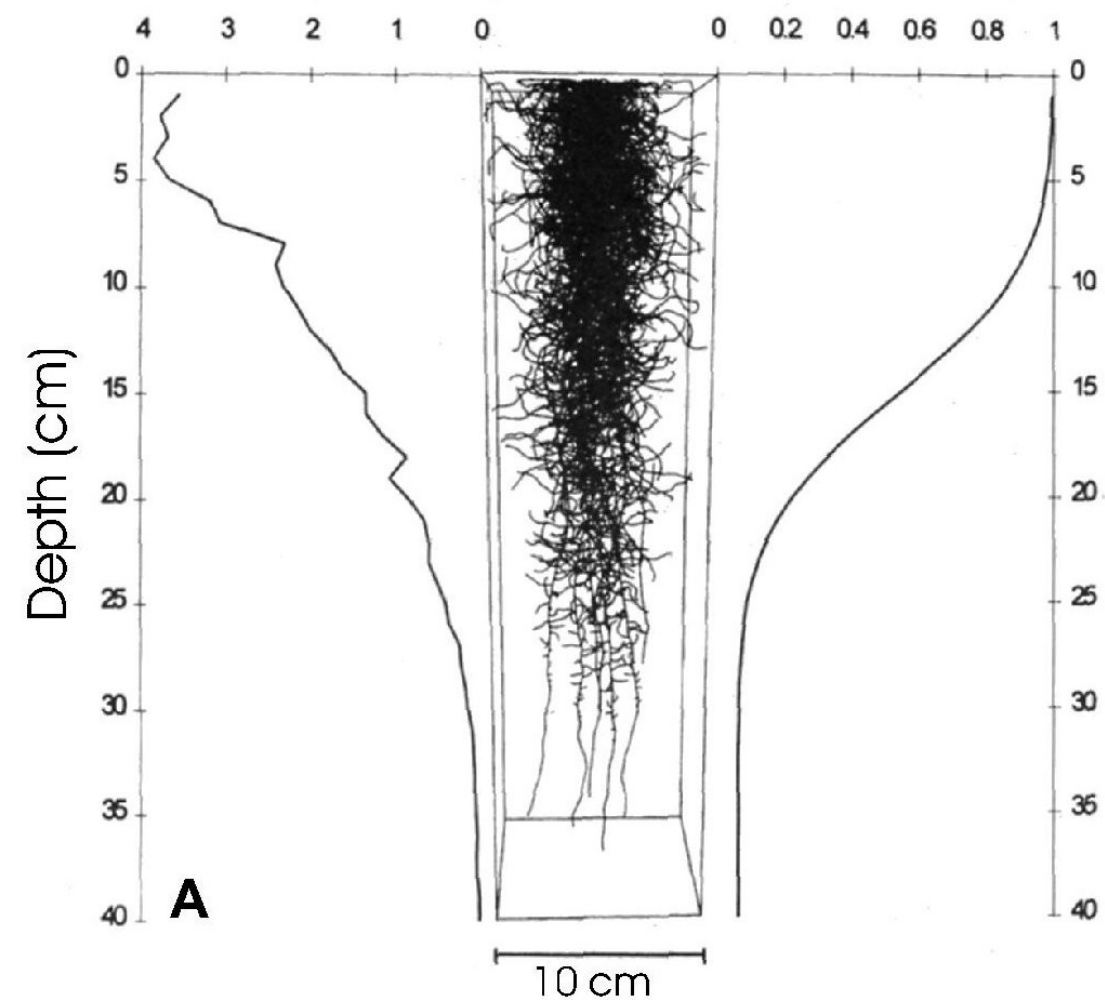

Root density $\left(\mathrm{cm} / \mathrm{cm}^{3}\right) \quad \mathrm{NO}_{3}$ concentration $\left.(\mu \mathrm{M} \mathrm{cm})^{-3}\right)$

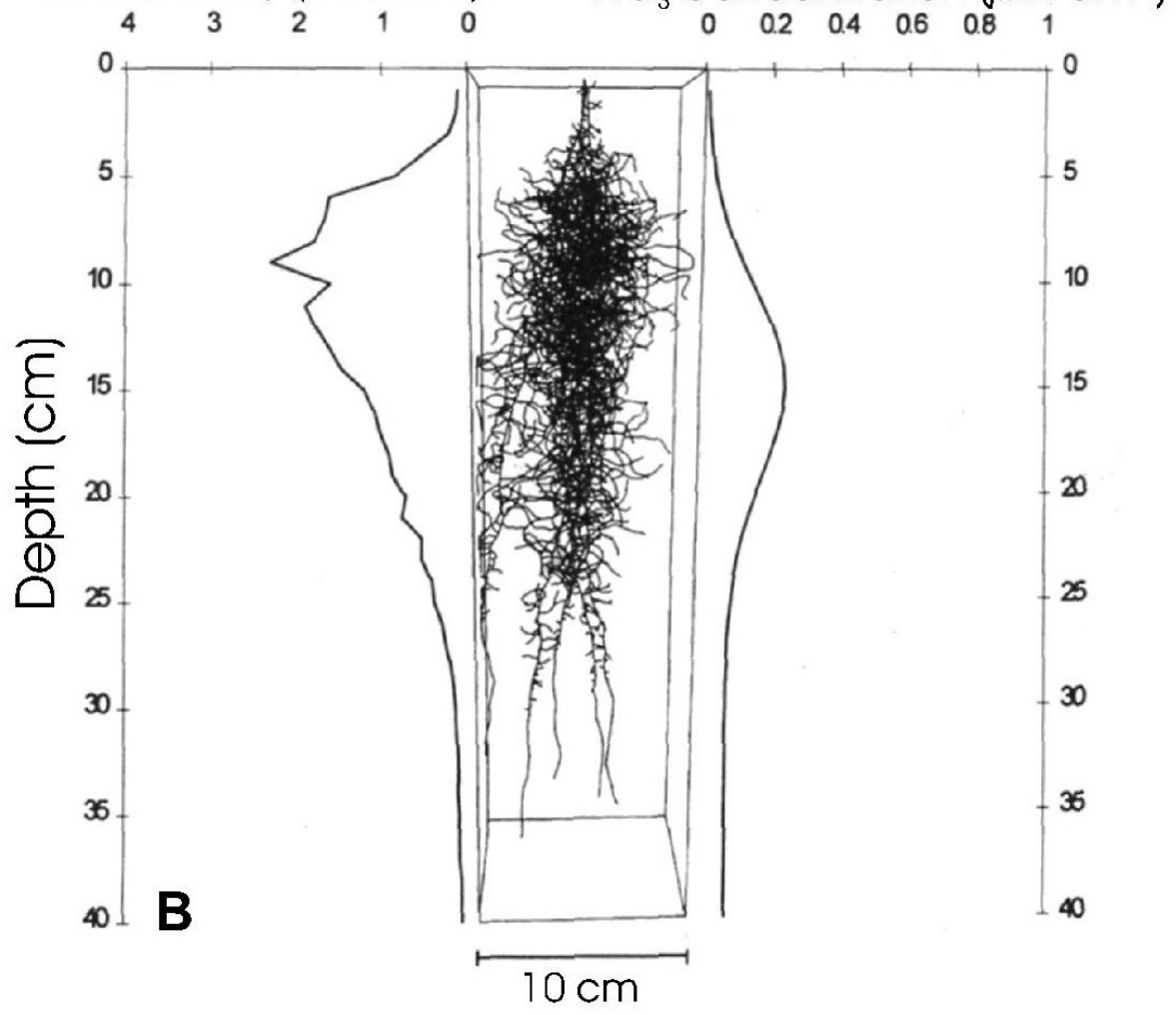

Figure 5 


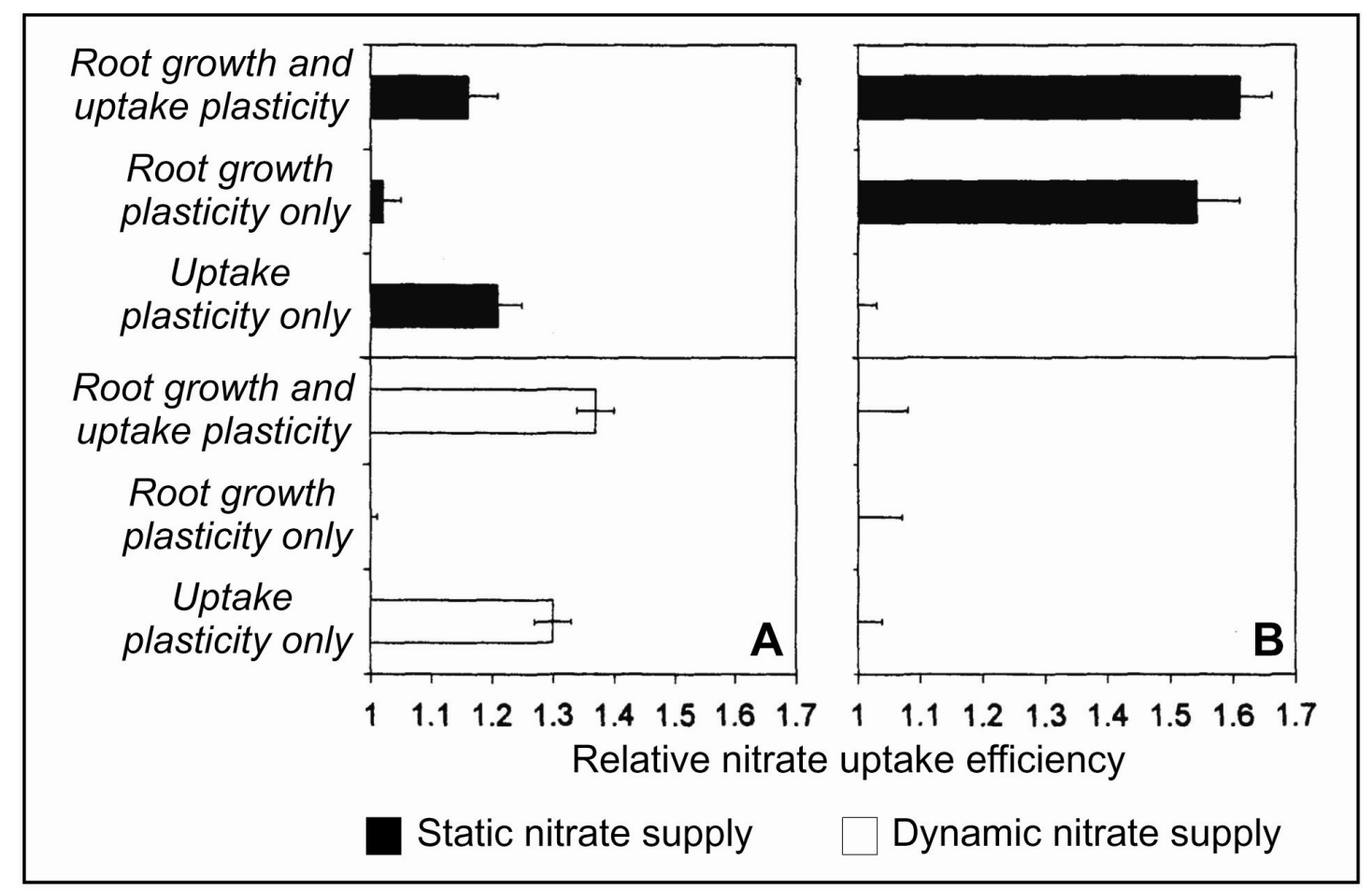

Figure 6 


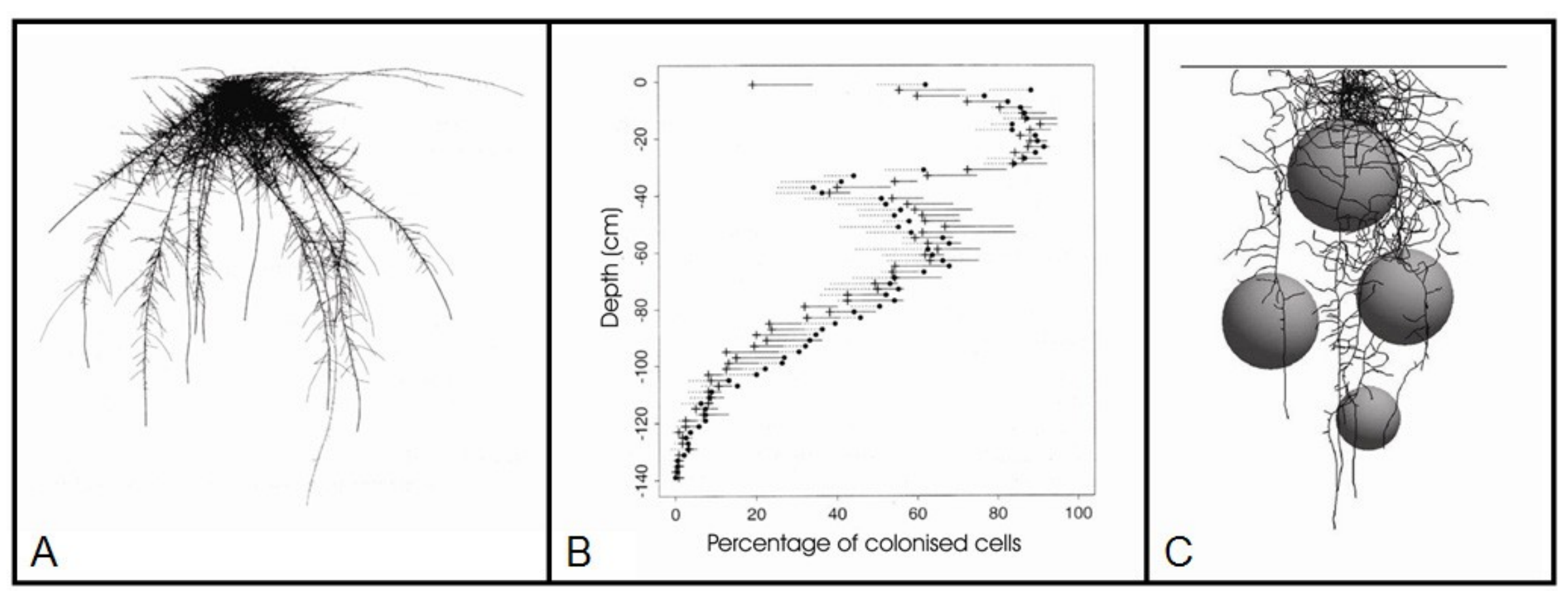

Figure 7 


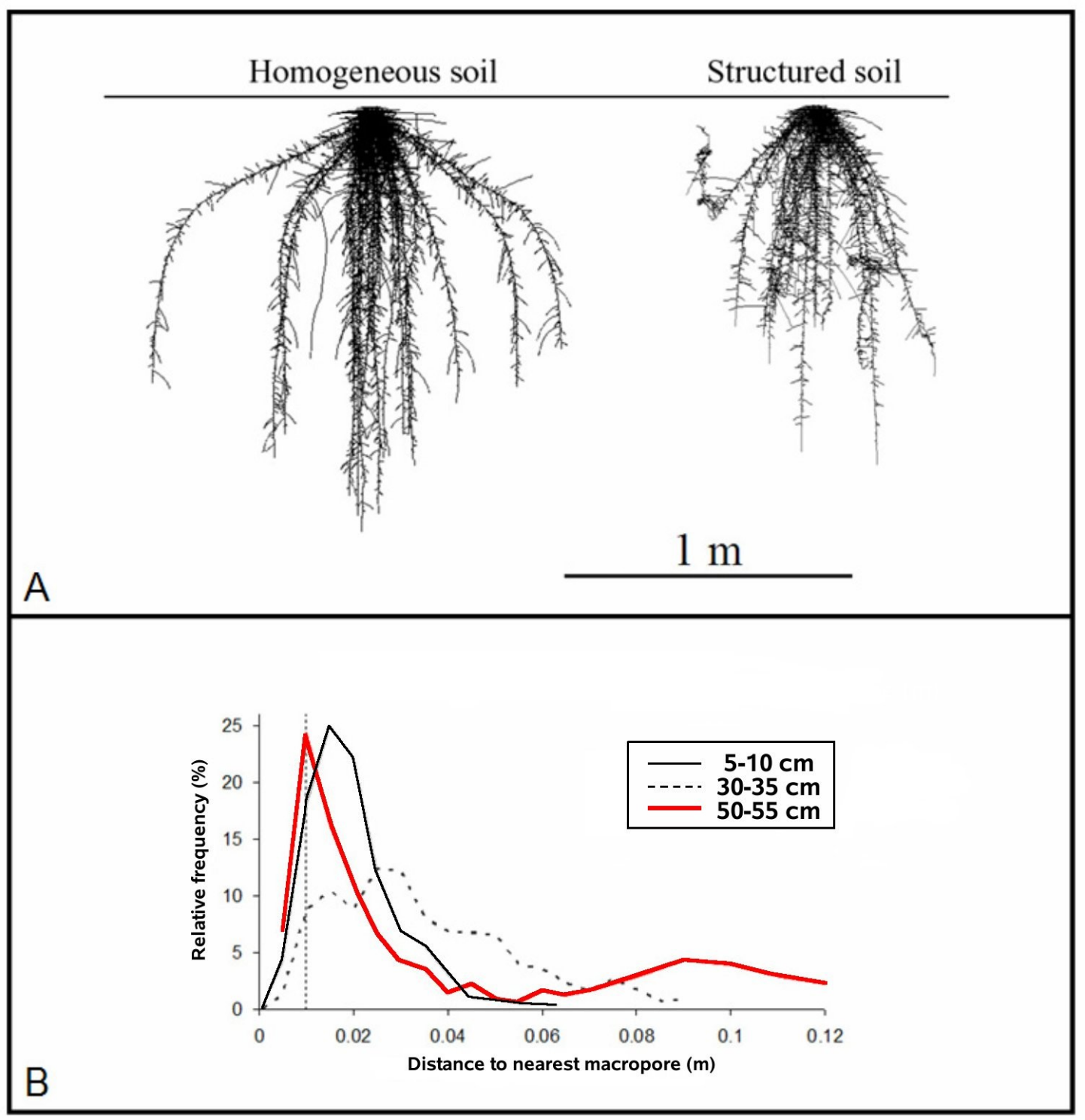

Figure 8 


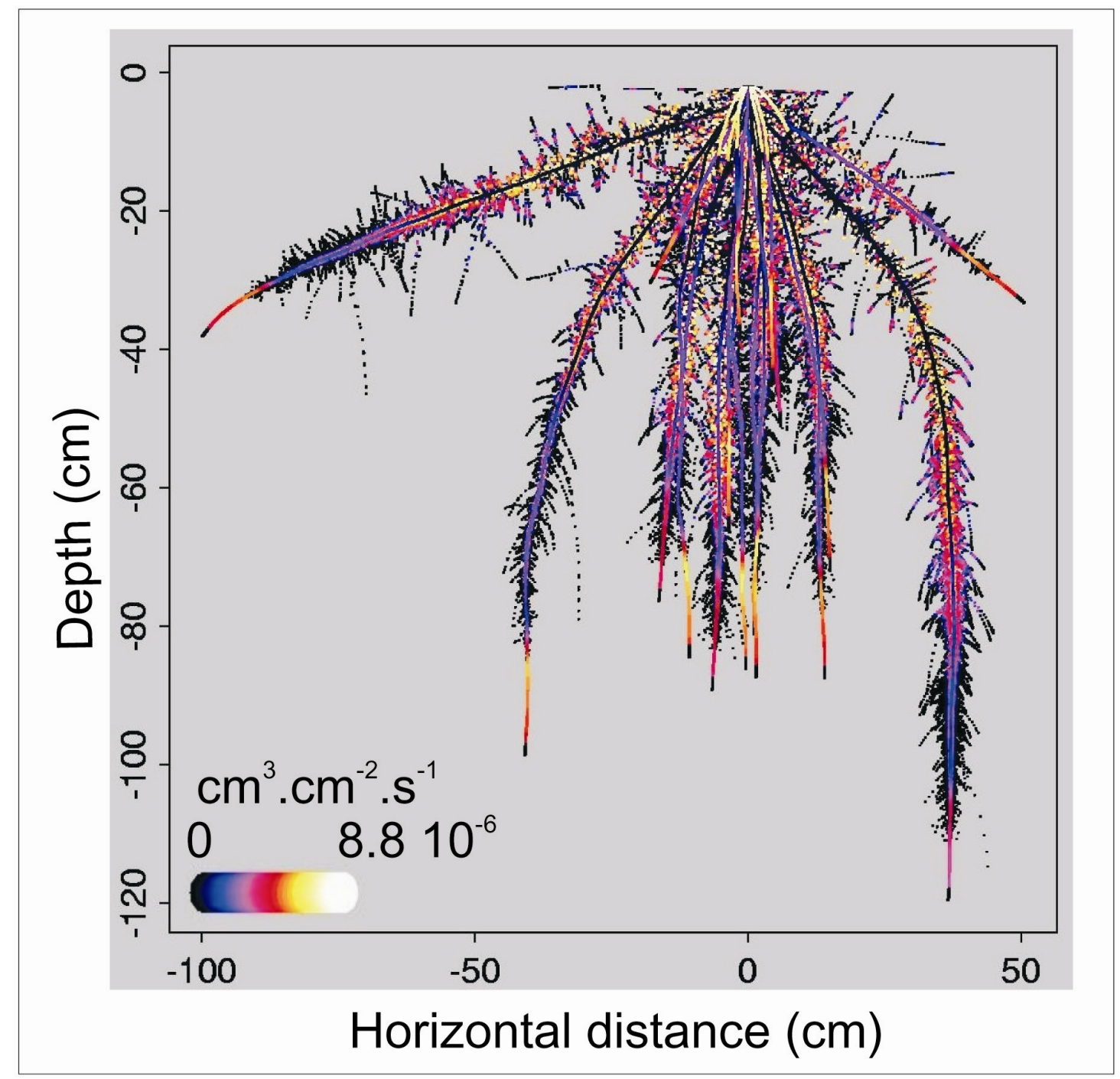

Figure 9 
$1.5 \mathrm{~h}$

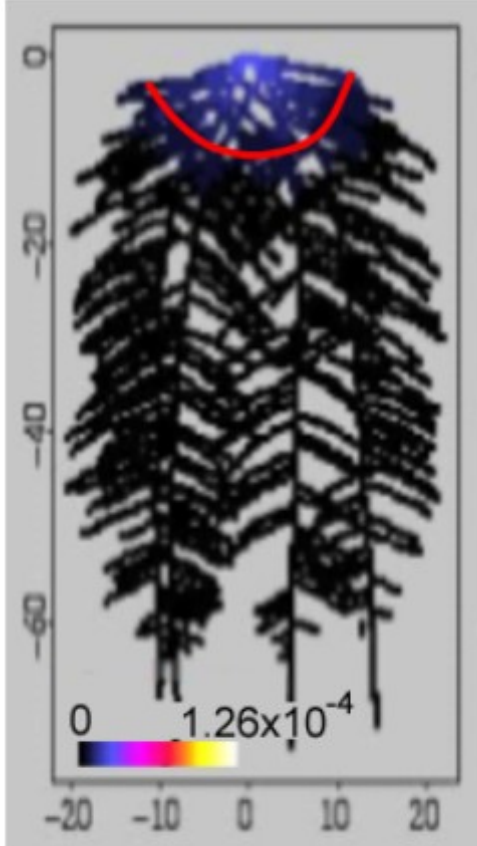

$5 \mathrm{~h}$

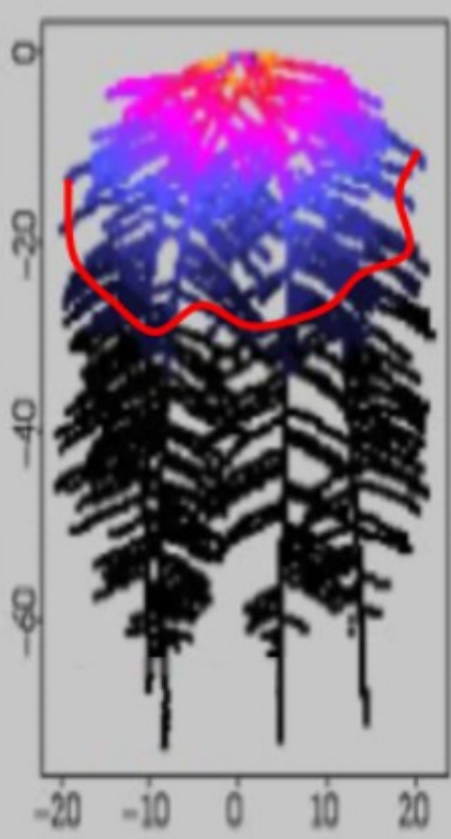

$7 \mathrm{~h}$
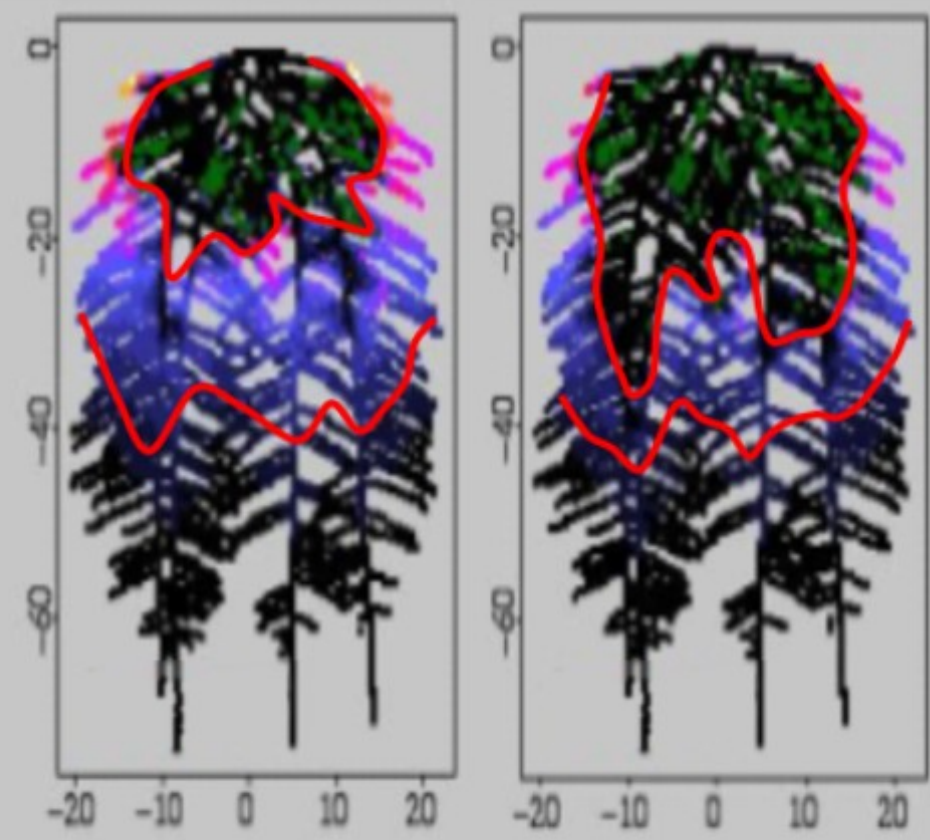

11.5h

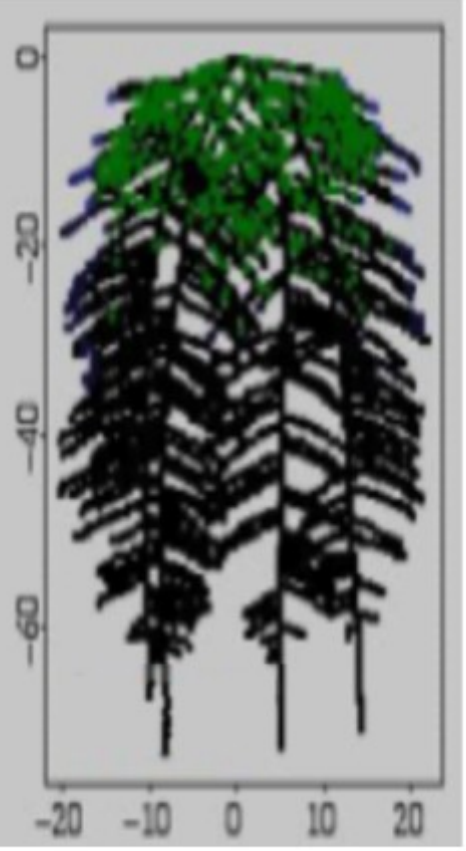

Figure 10 